
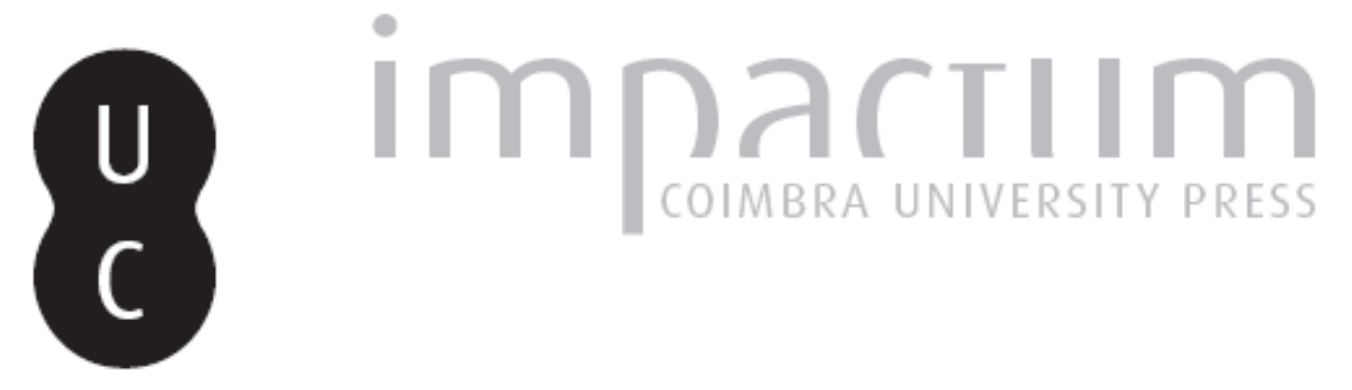

\title{
O lugar de Lucila Augusta no xadrez político da dinastia Antonina
}

\author{
Autor(es): $\quad$ Alves, Sérgio Lourosa
}

Publicado por: Centro de História da Universidade de Lisboa

URL persistente:

URI:http://hdl.handle.net/10316.2/23792

DOI:

DOI:http://dx.doi.org/10.14195/0871-9527_19_15

Accessed : $\quad$ 26-Apr-2023 04:15:56

A navegação consulta e descarregamento dos títulos inseridos nas Bibliotecas Digitais UC Digitalis, UC Pombalina e UC Impactum, pressupõem a aceitação plena e sem reservas dos Termos e Condições de Uso destas Bibliotecas Digitais, disponíveis em https://digitalis.uc.pt/pt-pt/termos.

Conforme exposto nos referidos Termos e Condições de Uso, o descarregamento de títulos de acesso restrito requer uma licença válida de autorização devendo o utilizador aceder ao(s) documento(s) a partir de um endereço de IP da instituição detentora da supramencionada licença.

Ao utilizador é apenas permitido o descarregamento para uso pessoal, pelo que o emprego do(s) título(s) descarregado(s) para outro fim, designadamente comercial, carece de autorização do respetivo autor ou editor da obra.

Na medida em que todas as obras da UC Digitalis se encontram protegidas pelo Código do Direito de Autor e Direitos Conexos e demais legislação aplicável, toda a cópia, parcial ou total, deste documento, nos casos em que é legalmente admitida, deverá conter ou fazer-se acompanhar por este aviso.

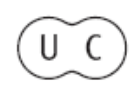



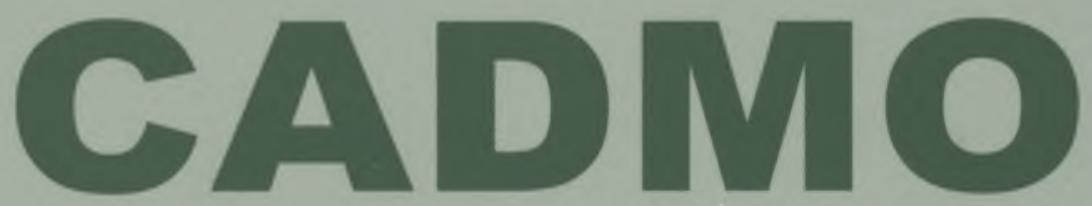

Revista de História Antiga

\author{
Centro de História \\ da Universidade de Lisboa
}

19

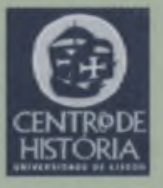

430 =

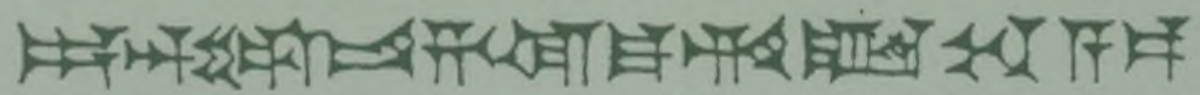

MHNIN AEI $\Delta$ E $\Theta E A ~ \Pi H \Lambda H I A \triangle E \Omega$ 


\title{
O LUGAR DE LUCILA AUGUSTA NO XADREZ POLÍTICO DA DINASTIA ANTONINA
}

\author{
SÉRGIO LOUROSA ALVES \\ Universidade de Lisboa \\ sergio.ruben.alves@gmail.com
}

\section{Resumo}

Lucila é uma personagem histórica que se enquadra na categoria das imperatrizes romanas. Todo o seu carácter está envolvido, contudo, em ambiguidade e subjectividade: posturas directamente relacionadas com o seu pai, marido e irmão, ou seja, Marco Aurélio, Lúcio Vero e Cómodo. Averiguando a sua presença no meio imperial, compreende-se o conceito de nobreza imperial e qual o contributo que Lucila traz para esta distinção. Apresenta-se Lucila como esposa de Lúcio Vero, percebendo como ganha o seu título de Augusta e quais as repercussões e intenções inerentes a este matrimónio. E demarca-se especialmente a conspiração que Lucila instigou sobre o seu irmão Cómodo por ser o ponto fundamental para a sua imagem forte e enigmática. Lucila, a filha, a mulher/Augusta, e a conspiradora. Todo o estudo tem por base três fontes antigas: a Historia Augusta, Díon Cássio e Herodiano.

Palavras-chave: Lucila Augusta; Historia Augusta; Díon Cássio; Herodiano.

\section{Abstract}

Lucilla is a historic character into the category of Roman empresses. Her whole nature is involved, however, an ambiguity and subjectivity: positions directly related to her father, husband and brother, namely Marcus Aurelius, Lucius Verus and Commodus. Examining her presence inside the imperial environment, the concept of imperial nobility and Lucilla's contribu- 
tions to this distinction can be perceived. Lucilla is presented as the wife of Lucius Verus, realizing how she wins the title of Augusta and which implications and intentions are inherent of this marriage. The conspiracy instigated by Lucilla against her brother Commodus is especially signalize because it basis her strong and enigmatic image. Lucilla, daughter, wife/Augusta, and plotter. This study is grounded on three ancient sources: Historia Augusta, Cassius Dio and Herodian.

Key-words: Lucilla Augusta; Historia Augusta; Cassius Dio; Herodian.

Lucila (148-182 d. C.) foi uma mulher da elite imperial romana, filha e esposa de imperadores e o elemento feminino de uma conspiração. Filha primogénita de Marco Aurélio e de Faustina Menor, Lucila recebeu o título de Augusta (164-169 d. C.) ao casar-se com o co-imperador Lúcio Vero. Esta filha de Marco Aurélio tornou-se uma figura carismática da história da Roma Antiga, desdobrando-se entre a solidez de carácter e o mistério.

A construção historiográfica desta mulher pode ser estudada fundamentalmente a partir da Historia Augusta, onde percebemos três tipos de imagens diferentes, em concordância com as informações presentes nas Vita Marci, Vita Veri e Vita Commodi. Isso significa que é possível apreender uma imagem de Lucila enquanto filha, mulher, imperatriz e Augusta.

Lucila nasceu no momento em que Marco Aurélio vivia alguns dos maiores acontecimentos da sua vida: a morte de Adriano em Baias; o casamento com Faustina; e a entrega do poder de tribuno e procônsul para fora da Cidade ${ }^{(1)}$. Quando Antonino Pio morreu, Marco Aurélio foi nomeado seu sucessor e decidiu dividir o poder com o irmão, Lúcio Vero. Ambos tinham sido adoptados por Antonino Pio, que deu a um o nome de Lúcio Aurélio Vero Cómodo e a ambos os títulos de Caesar e Augustus. Lucila foi incluída neste "projecto", a primeira vez em que o Império Romano foi governado por dois imperadores em equivalentes termos, uma vez que o seu pai fez com que ela se casasse com o tio, Lúcio Vero(2). De certa forma, Aurélio dividiu o poder com o seu irmão, mas fortaleceu o vínculo e assegurou um certo domínio sobre ele ao casá-lo com a sua filha mais velha. Foi por esta via que Lucila se viu inscrita na categoria das imperatrizes, pois ao casar-se com Lúcio Vero ganhou o título de Augusta $^{(3)}$.

Herodiano, retórico sírio, refere também o casamento de Lucila com Vero como vector de associação do poder dividido entre os dois 
imperadores: "Ao casar Lucila com Lúcio, Marco fez com que este casamento fosse um laço forte de boa vontade mútua.»(4) E Díon Cássio, o historiador-senador, relaciona este casamento com o facto de Lúcio Vero ter tido a função de dirigir a guerra contra os Partos: «Marco tornou-o, portanto, mais próximo ao casá-lo com a sua filha Lucila, e enviou-o para conduzir a guerra contra os Partos.»(5) Enquanto o co-imperador esteve na Síria, viu o seu nome envolvido em rumores de uma vida desenfreada, de grandes festas a adultérios, incluindo casos amorosos com jovens rapazes ${ }^{(6)}$. Poderá ser o cariz orientalizante a configurá-lo desta forma, mas parece que Marco Aurélio decidiu mandar a filha para junto do seu irmão e marido dela a fim de o controlar e não a desonrar. Na Historia Augusta sugere-se também que, no decurso da guerra com os Partos, Lúcio Vero se revelou ser um fraco porque, enquanto as tropas combatiam as revoltas da Síria e as legiões se sentiam estranguladas, o imperador destacado divertia-se a caçar pela Apúlia, a viajar por Atenas e Corinto (acompanhado de orquestras e cantores), ou a galantear-se pelas cidades da costa da Ásia, como a Panfília e a Cilícia, onde constituíra autênticos resorts de prazer ${ }^{(7)}$.

Durante quatro anos, pelo menos, Lúcio Vero passou os Invernos na Laodiceia, os Verões em Dafne e o resto do tempo em Antioquia. Com esta forma de estar, foi muitas vezes objecto de ridículo, mesmo com os Partos controlados, pois, sempre que se celebravam os Saturnalia, preferia o convívio animado com escravos. Finalmente, e por insistência da sua comitiva, estabeleceu-se perto do Eufrates, mas, pouco tempo depois, com a ordem de receber Lucila, enviada pelo seu pai, teria regressado a Éfeso. Pensando que Marco Aurélio acompanhara a sua filha, como este teria dito ao senado, dirigiu-se prontamente para Éfeso, pois receava que a sua conduta fosse descoberta. Refere-se ainda que o co-imperador teria regressado a Roma sem barba $^{(8)}$, tendo-a rapado na Síria, para satisfazer um capricho de uma senhora de baixa estirpe. Estes são alguns exemplos dos rumores que corriam sobre Vero, partindo das populações da Síria e dispersando-se por todo o império: "Tanto quanto circulava entre os Sírios, era objecto de ridículo, e muitas piadas sobre ele eram preservadas ${ }^{(9)}$.

Sobre a morte de Vero, mais rumores são apresentados, envolvendo-se Lucila nos mesmos. Quando a guerra germânica rebentou, os dois imperadores foram juntos para a frente de combate, pois Aurélio não queria enviar Lúcio Vero novamente sozinho, dada a sua conhecida devassidão, e uma vez que também não pretendia deixá-lo 
em Roma. Não muito longe de Altino, de um momento para o outro, Vero ficou gravemente doente, falando-se logo em apoplexia, pois teria saído da sua carruagem a sangrar. Lúcio Vero foi levado para Altino, onde acabou por morrer, depois de ter vivido três dias sem poder falar ${ }^{(10)}$. É então que se menciona a possibilidade de Lúcio Vero ter violado Faustina, a cunhada e mãe de Lucila e mulher de Marco Aurélio. Por essa razão, a imperatriz teria envenenado as ostras que estavam destinadas ao co-imperador. Mas a sua morte é também atribuída à própria Lucila, que temeria a perda de poder enquanto imperatriz ao saber que Lúcio Vero se teria envolvido com uma irmã dele de nome Fábia. De facto, Vero e Fábia haviam-se tornado tão íntimos que todo este rumor se desenvolveu num plano superior, levantando-se mesmo a hipótese de juntos terem conspirado contra Aurélio(11).

Após a morte de Vero, Marco Aurélio casou novamente Lucila, mas desta vez com Cláudio Pompeiano, filho de um soldado romano. Saliente-se que, sendo o noivo um mero nativo de Antioquia e o seu nascimento não suficientemente nobre, o imperador acabou por fazê-lo duas vezes cônsul|(12). A esta nomeação não deverá ter sido estranho o facto de a filha de Aurélio ser uma Augusta e filha de uma Augusta. Herodiano menciona este segundo casamento com Pompeiano salientando o facto de Lucila ter ficado privada de todos os privilégios da sua posição imperial(13).

Lucila e o seu segundo casamento podem ser encarados como o contexto de um bom exemplo da virtude nobiliárquica do consulado, pois verifica-se que a filiação consular surge em favor recorrente dos próprios nobres romanos. Neste sentido, a menção de filiação não é, todavia, o único procedimento posto em prática para conceder nobreza, sendo somente utilizada em certas ocasiões. O imperador deu a mão da filha em casamento a um plebeu militar, Cláudio Pompeiano, e, para reforçar a sua nobilitação, conferiu um segundo consulado ao genro. Ao tornar-se cônsul, Pompeiano angariou a possibilidade de atingir a nobilitas, sobretudo através da esposa, que era não somente filha de Marco Aurélio, como também a viúva de Lúcio Vero. Esta dupla possibilidade, proveniente de elementos do próprio consulado, fortalece a própria nobreza. A fórmula facere consulum faz evidentemente eco da conjuntura facere nobilem e facere genus, uma vez que, ao nomear alguém cônsul com tais objectivos, passa a ser o imperador que reclama para si o acto de criador de nobilitas ${ }^{(14)}$.

Isoladamente, os Antoninos conseguiram conciliar as contrariedades de transmissão de poder através do recurso sistemático à adopção, 
apelidando-se esta dinastia como adoptiva. As ideologias do regime proclamaram que a escolha do melhor guiava, desde logo, a selecção do herdeiro ao trono. Um tal discurso, contudo, dissimulava a lógica familiar do sistema, concedendo ao soberano a possibilidade de fazer uma escolha num círculo fechado de amigos/parentes, e de reforçar esse laço através do casamento entre um herdeiro escolhido e uma das suas filhas ou uma prima próxima. Poderia o segundo casamento de Lucila indicar a escolha mais certa para Marco Aurélio? Um acaso imprevisto - a ausência de filhos nos primeiros quatro imperadores desta dinastia - permitiu este funcionamento de compromisso ambíguo durante um século inteiro, até voltar a existir um filho directo do imperador apto a governar, nomeadamente Cómodo (180-192), filho e sucessor de Marco Aurélio, que destruiu o equilíbrio deste sistema de adopção(15).

As mulheres podiam, também, desde cedo, transmitir a nobreza imperial, mas esta sua função nunca é apresentada nas fontes históricas, que acabam por somente enumerar os ascendentes masculinos. No caso de Lucila, verifica-se uma nobreza construída a partir, evidentemente, do facto de ser filha de Marco Aurélio e Augusta. Ainda assim, a mensagem imperial podia não ser seguida pelas elites romanas, pois, em outro plano, decidiam somente descrever o que thes dizia respeito, seguindo as suas próprias perspectivas. As fontes latinas, particularmente com influência senatorial como a Historia Augusta ou Díon Cássio, parecem pouco sensíveis à especialidade da nobreza imperial, ficando-se por uma diferença de gradação, mas não de natureza, pois interessava mais tratar a nobreza dos senadores ${ }^{(16)}$.

A partir da Historia Augusta, pode verificar-se que Lúcio Vero deve a sua nobreza a uma ascendência consular (além da incontornável adopção), não interessando as fontes de nobreza, pois os príncipes e os senadores eram associados a um estatuto nobre comum ou similar. A nobilitas adquirida pelo nouus Cláudio Pompeiano é igualada à nobreza da própria Lucila, filha de um imperador e de uma Augusta. A superioridade da princesa não é contestada, mas a atribuição de um segundo consulado a Pompeiano (173 d. C.) é, por forma natural, uma redução da distância entre os dois cônjuges. Pode até chegar-se ao ponto de comparar a nobreza de Antonino (138-161 d. C.) e a de Marco Aurélio (161-180 d. C.) como sendo de igual valor, mesmo que o discurso imperial subordine a nobreza do segundo à do primeiro, pois Antonino Pio tinha adoptado Aurélio. Por outro lado, Herodiano foca-se mais em apresentar a nobreza de um amante de Lucila, 
já no contexto de ser irmã de Cómodo, designadamente Quadrado, que descendia por duas vias de uma família consular: filho biológico de Cláudio Severo, segundo cônsul ordinário em 173 d. C., e filho adoptivo de Marco Quadrado, cônsul ordinário em 164 d. C. ${ }^{(17)}$

Lucila morreu na sequência de mais uma conspiração ou rumor de tal. Entenda-se, primeiramente, o que proporcionou esta conjura. Apesar de Aurélio ter feito todos os esforços para que Cómodo tivesse uma boa educação e, assim, se tornasse um homem melhor, o seu herdeiro demonstrou desde cedo ter um carácter que se poderá caracterizar como mau e desonroso, cruel e lascivo, provocador e insolente, e, sobretudo, corrupto. É esta a perspectiva das fontes. $\mathrm{Na}$ Historia Augusta são apresentados os vários títulos e as responsabilidades que the são atribuídas, mostrando que quanto mais honroso se tornava, mais maligna se tornava a sua conduta. Salienta-se uma conduta lasciva e obscena no palácio imperial, fazendo-se rodear de prostitutas e mulheres bonitas, e um desrespeito pelos deveres imperiais, sendo detestado pelo senado. O novo imperador de Roma movia-se pela crueldade e pela destruição de grande ordem, tornando-se sedento de sangue. Existe um culminar de todas as suas atitudes e particularidades de carácter no acontecimento que envolve Lucila. Escreve o autor da Historia Augusta: «Rodeava-se de mulheres de rara beleza, mantendo-as como prostitutas como uma espécie de bordel de violação de castidade. [...] As acções de Cómodo levaram Lucila e Quadrado, com o apoio de Tarruténio Paterno, o prefeito da guarda, a planear o seu assassinato. "(18)

Por outro lado, Herodiano concentra estes antecedentes da conspiração na figura de Perene, o prefeito do pretório. Cómodo afastou os conselheiros destinados pelo seu pai, pois Perene satisfazia todos os seus apetites juvenis, encarregando-o de todos os assuntos do principado. Perene, conduzido pela sua cobiça e ambição insaciáveis, levantou várias suspeitas sobre as pessoas mais eminentes da elite romana, despertando assim os medos e receios do imperador, e providenciando ao jovem as razões e as oportunidades para destruir e confiscar as propriedades daqueles que queria atingir ${ }^{(19)}$.

A conduta lasciva de Cómodo pode ter sido o motivo para Lucila ter conspirado contra o irmão mais novo. Lemos nas fontes: «Por fim, as atitudes de Cómodo levaram Quadrado e Lucila a planear o assassinato [...]» (SHA, Com. 4, 1); «Foi a razão porque ela [Lucila] o persuadiu [Pompeiano] a atacar Cómodo." (D. C. 72, 1 5); "Então, um golpe de má sorte alterou por completo a sua postura leve, mas moderada" 
(Hdn. 1, 8, 3). Efectivamente, segundo a Historia Augusta, Quadrado (possivelmente neto da irmã de Marco Aurélio) e Lucila, com o apoio de Tarruténio Paterno, o perfeito da guarda imperial, formam um plano para assassinar Cómodo. A tarefa de assassínio foi entregue a Cláudio Pompeiano (aparentemente Cláudio Pompeiano Quinciano), filho do segundo marido de Lucila. Este, próximo de ter a oportunidade de cumprir a sua missão, dirigiu-se com grandes passadas a Cómodo com uma espada e, quando estava prestes a acertar em cheio, disse: "O senado envia-te este punhal.» ${ }^{(20)}$ Pompeiano denunciou a conspiração, falhando a realização do plano, no qual muitos outros estavam implicados. Após este fiasco, Pompeiano e Quadrado foram logo executados, de seguida Norbano e Parálio. Lucila foi enviada para o exílio em Cápreas, onde acabou por morrer ${ }^{(21)}$.

Herodiano propõe outro motivo e relata os acontecimentos desta conjura de forma diferente. Cómodo permitiu primeiramente que a sua irmã mantivesse as honras imperiais como Augusta, continuando a ocupar o lugar imperial nos teatros e que o fogo sagrado fosse carregado antes de si. Entretanto, quando Cómodo se casou com Crispina ${ }^{(22)}$, o costume mandava que o lugar principal nos teatros fosse entregue à imperatriz efectivamente em vigor. Lucila deve certamente ter encontrado dificuldade em tolerar este tipo de situações e sentiu que nenhuma honra era prestada à sua majestade, tomando-o como um insulto. $\mathrm{E}$, desde que se apercebeu que o seu marido Pompeiano era devoto de Cómodo, não the contou nada sobre os seus planos de tomar o controlo do império. Lucila testou, então, os sentimentos de um jovem vigoroso e nobre, Quadrado, com quem circulavam rumores de ser amante em segredo, argumentando determinadamente em torno do facto da sua imperial precedência. Ao conseguir persuadir o jovem a pôr em prática a conspiração, acabou por provocar a sua destruição e a de todo o senado.

O retórico sírio avança também intervenientes diferentes. Quadrado, seleccionando alguns confederados entre o proeminente senado, teria convencido Quinciano, um jovem senador arrojado e temerário, a esconder um punhal entre a sua túnica, esperando por um determinado tempo e lugar, para apunhalar Cómodo. Assegurou, assim, que Quinciano manteria o assunto em segredo dentro do senado através de subornos $^{(23)}$.

Díon Cássio descreve estes acontecimentos de outra forma, colocando Cláudio Pompeiano como o organizador/executante da conspiração. Quando estava numa estreita entrada do anfiteatro, teria impelido 
uma espada e dito: "Vê! Isto é o que o senado te envia.»(24) Pode, assim, inferir-se que, apesar de Díon explicitar que assistiu aos acontecimentos, as outras duas fontes concordam que Quinciano é o assassino enviado. Mas a circunstância e a expressão retratadas são equivalentes nas três fontes antigas. Lucila é caracterizada como uma pessoa nada modesta ou casta, tal como o seu irmão Cómodo, detestando o seu segundo marido Pompeiano. Teria sido este o motivo pelo qual teria persuadido o marido a fazer o ataque contra Cómodo (que se tornara muito próximo do Princeps), acabando não só por causar a destruição de Pompeiano, como também a sua, uma vez que a fonte da conspiração teria sido detectada.

Com o perigo iminente no palácio, Cómodo ter-se-ia isolado, matando os seus próprios agentes privados. Tudo o que envolveu esta conjura transtornou o imperador: raramente aparecia em público e excepcionalmente recebia mensagens. A menos que passassem antes pelas mãos de Perene ${ }^{(25)}$. Em relação a Paterno, o possível incitador do assassínio, continuou a pensar-se que teria sido um mero cúmplice da conspiração, e que, certamente, teria pensado em prevenir-se contra qualquer forma de o poderem acusar.

Pode verificar-se, então, que toda a acção incitada por Lucila terá potenciado outros tipos de rumores e conjurações. Cómodo declarou, sem misericórdia, a morte da própria irmã. Diz o autor antigo: "Cómodo, por sua vontade, matou a sua irmã Lucila, depois de a exilar em Cápreas.»(26) Antes, portanto, tê-la-ia afastado de todos os que estavam envolvidos na conspiração e de todos os que estavam sob qualquer e mínima suspeita. Saliente-se que qualquer que tenha sido o motivo de Lucila, não podia decerto ser ultrajada publicamente pelo irmão. A solução para a morte da imperatriz definiu-se com o exílio, onde acabou por ser executada(27).

Lucila é sem dúvida uma personagem marcante da história da Roma Antiga. Ficou para a posterioridade pela tentativa de conspiração que incitou contra o irmão Cómodo, evidenciando um carácter forte, perseverança e audácia, envolvidos em sede de poder. Todas estas informações concretizam a sua construção historiográfica e as três fontes históricas corroboram, de uma maneira ou de outra, esta tentativa de assassinato.

Nesta medida, Lucila ganhou um estigma que perdura até aos dias de hoje. No cinema contemporâneo, este episódio histórico foi retratado em dois filmes: The Fall of the Roman Empire (de Anthony Mann, 1964) e Gladiator (de Ridley Scott, 2000). No primeiro, Lucila 
foi interpretada por Sophia Loren, ícone de beleza dos anos 60-70; no segundo, por Connie Nielsen. Mas dificilmente algum dos filmes fará justiça à importância que a imperatriz teve no xadrez político do seu tempo.

The Fall of the Roman Empire é tido, até hoje, como um desastre cinematográfico, graças ao produtor Samuel Bronston. Neste filme, a personagem de Lucila é muito mais evidenciada do que em Gladiator, na medida em que existe a tentativa de alcançar um exagerado drama histórico, demarcando a realidade das intrigas políticas, nas quais resulta a conhecida dissolução da "Glória que foi Roma". Sophia Loren, como Lucila, tenta persuadir Lívio, filho adoptado e sucessor pretendido por Marco Aurélio (Alec Guinness), a tomar o poder em vez do colérico e egoísta Cómodo, mas Lívio não toma parte deste intento. Este decide somente intervir quando se apercebe que Cómodo quer matar Lucila, mulher que ganhava cada vez mais poder. Pretendendo encontrar um terreno comum entre incidentes históricos e cenas de acção, The Fall of the Roman Empire é hoje visto como um clássico. Em 1964, contudo, as audiências não foram numerosas, como aconteceu com outros filmes épicos da altura. Falhou redondamente nos resultados, não conseguindo justificar os exorbitantes custos despendidos na sua produção. O filme ainda ganhou um "Globo de Ouro" para a banda sonora, a cargo de Dimitri Tiomkin, e foi nomeado na mesma categoria para os óscares. O desastre financeiro a que deu origem terminou com o sonho do produtor Samuel Bronston de criar um centro de produção cinematográfica de filmes histórico-épicos.

Gladiator tem um argumento similar, partindo aproximadamente das mesmas personagens históricas. Neste filme, a personagem de Lucila, interpretada por Connie Nielsen, tem uma postura menos evidente, mantendo-se um clima denso de conspiração em seu redor, e sendo ainda pressuposta uma relação mais afectiva entre Lucila e o seu irmão Cómodo (Joaquin Phoenix). Este filme, contudo, centra-se na figura de Máximo (Russell Crowe), um general tornado gladiador, privilegiando um enredo menos histórico, mas que lhe valeu cinco óscares da Academia, incluindo o de melhor filme e melhor actor para Crowe. Além disso, revigorou na indústria cinematográfica o filme épico-histórico, o que deu origem aos subsequentes Troy, Alexander e 300.

Ambos os filmes relatam o assassinato de Marco Aurélio e a subida ao poder de Cómodo ${ }^{(28)}$, no momento em que este fica a saber que o pai pretendia apontar Lívio/Máximo como sucessor. Mas as perspectivas contemporâneas nem sempre andam pari passu com as antigas. 
$\mathrm{Na}$ historiografia antiga, Lucila emerge como meio de atribuição nobiliárquica; como elemento de união na associação de poder entre dois imperadores; como controladora dos devaneios do marido; como protagonista de rumores de morte; e como iniciadora de conspiração. A sua imagem transfere-se de uma postura mais passiva para um posição mais activa, numa gradação ou crescendo historiográfico assente em essencialmente três perspectivas: filha, mulher/Augusta e conspiradora.

\section{Notas}

(1) SHA, Marc. 4, 1. Ser procônsul fora da Cidade permitia-lhe ter o direito de fazer cinco propostas perante o senado, pois o imperador era regularmente autorizado pelo senatus consultum a propor um definido número de medidas em cada reunião, tendo estas propostas precedência sob as outras. Sabe-se que o seu número podia variar, mas não passariam de mais do que cinco.

(2) SHA, Marc. 7, 5.

(3) SHA, Marc. 7, 7.

(4) Hdn. 1, 8, 3 .

(5) D. C. $71,1,3$.

(6) SHA, Ver. 4, 4.

(7) SHA, Ver. 7, 1.

(8) Ao rapar a sua barba, Lúcio Vero anulava a característica helenística comum a todos os imperadores Antoninos.

(9) SHA, Ver. 7, 4.

(10) SHA, Ver. 9, 11.

(11) SHA, Ver. 10-11.

(12) SHA, Marc. 20, 6.

(13) Hdn. 1, 8, 3.

(14) C. BADEL, La Noblesse de l'Empire Romain: les masques et la vetu, Champ Vallon, 2005, 78-79.

(15) Idem, ibidem, 204-205.

(16) Idem, ibidem, 246-249.

(17) Idem, ibidem, 302.

(18) SHA, Com. 2, 8, e 4, 1, respectivamente.

(19) Ainda assim, Herodiano atenua a imagem negativa de Cómodo, atribuindo-Ihe alguma bondade, rapidamente esquecida quando sente que a sua vida corria perigo.

(20) SHA, Com. 4, 3.

(21) SHA, Com. 1-5. 
(22) Note-se que, embora Herodiano sugira que Cómodo e Crispina casaram depois da sua subida ao poder em 180, o casamento deu-se em 178. Uma discrepância temporal que abala a veracidade das informações do retórico sírio.

(23) Hdn. 1, 8, 5.

(24) D. C. $72,4,4$.

(25) SHA, Com. $5,1$.

(26) SHA, Com. 5, 7-8.

(27) Hdn. 1, 8, 8.

(28) J. L. BRANDÃO, "O Gladiador: um filme com possibilidades didácticas", BEC 33, 2000, 147-150. 